\title{
REAL-TIME CANISTER WELDING HEALTH MONITORING AND PREDICTION SYSTEM FOR SPENT FUEL DRY STORAGE
}

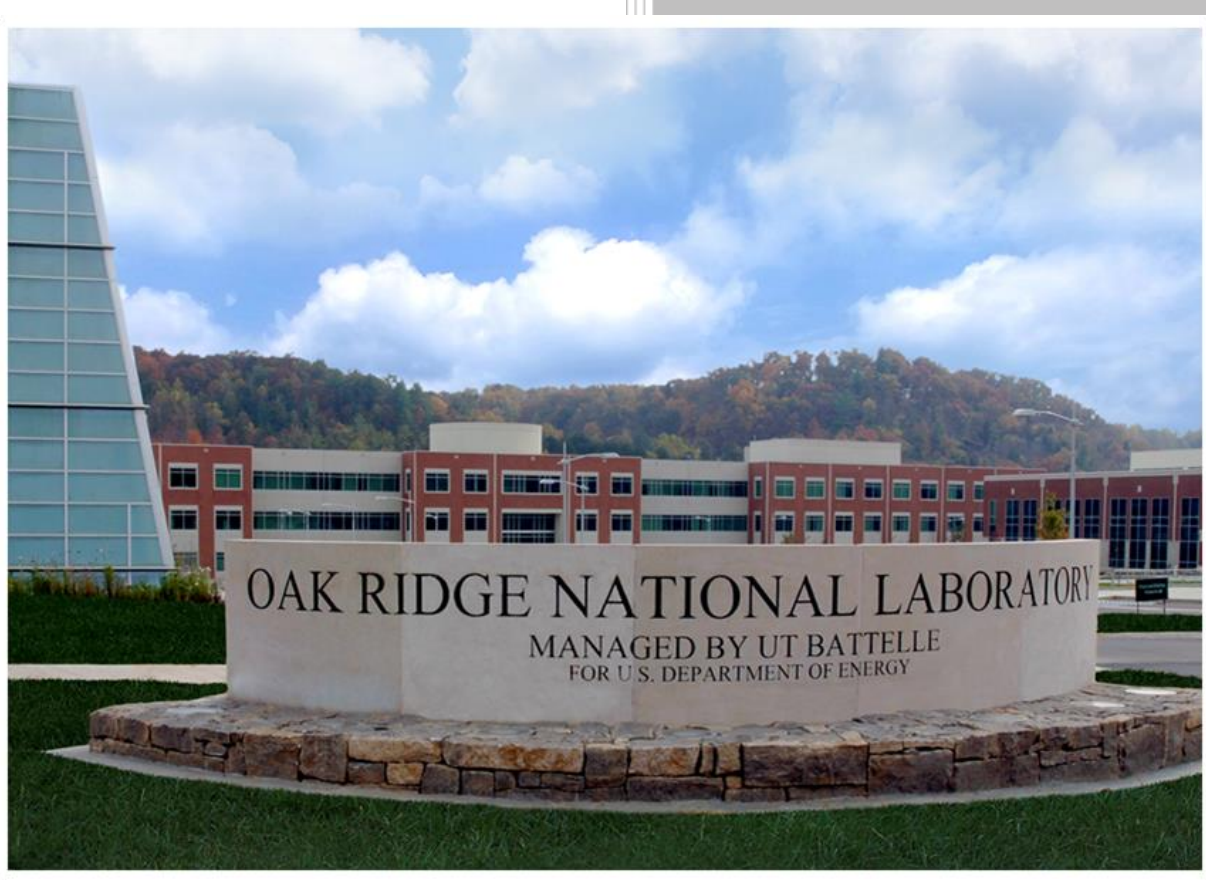

\section{Approved for public release.} Distribution is unlimited

Wei Tang

Stylianos Chatzidakis

July 2020 


\title{
DOCUMENT AVAILABILITY
}

Reports produced after January 1, 1996, are generally available free via US Department of Energy (DOE) SciTech Connect.

Website www.osti.gov

Reports produced before January 1, 1996, may be purchased by members of the public from the following source:

\author{
National Technical Information Service \\ 5285 Port Royal Road \\ Springfield, VA 22161 \\ Telephone 703-605-6000 (1-800-553-6847) \\ TDD 703-487-4639 \\ Fax 703-605-6900 \\ E-mail info@ntis.gov \\ Website http://classic.ntis.gov/
}

Reports are available to DOE employees, DOE contractors, Energy Technology Data Exchange representatives, and International Nuclear Information System representatives from the following source:

Office of Scientific and Technical Information

PO Box 62

Oak Ridge, TN 37831

Telephone 865-576-8401

Fax 865-576-5728

E-mail reports@osti.gov

Website http://www.osti.gov/contact.html

This report was prepared as an account of work sponsored by an agency of the United States Government. Neither the United States Government nor any agency thereof, nor any of their employees, makes any warranty, express or implied, or assumes any legal liability or responsibility for the accuracy, completeness, or usefulness of any information, apparatus, product, or process disclosed, or represents that its use would not infringe privately owned rights. Reference herein to any specific commercial product, process, or service by trade name, trademark, manufacturer, or otherwise, does not necessarily constitute or imply its endorsement, recommendation, or favoring by the United States Government or any agency thereof. The views and opinions of authors expressed herein do not necessarily state or reflect those of the United States Government or any agency thereof. 
Materials Science and Technology Division

Reactor and Nuclear Systems Division

\title{
REAL-TIME CANISTER WELDING HEALTH MONITORING AND PREDICTION SYSTEM FOR SPENT FUEL DRY STORAGE
}

\author{
Wei Tang and Stylianos Chatzidakis
}

Date Published: July 2020

\author{
Prepared by \\ OAK RIDGE NATIONAL LABORATORY \\ Oak Ridge, TN 37831-6283 \\ managed by \\ UT-BATTELLE, LLC \\ for the \\ US DEPARTMENT OF ENERGY \\ under contract DE-AC05-00OR22725
}





\section{CONTENTS}

CONTENTS

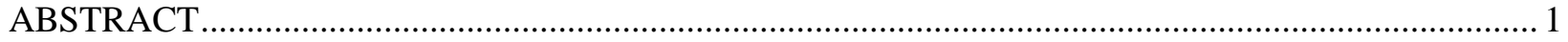

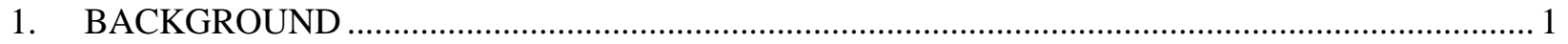

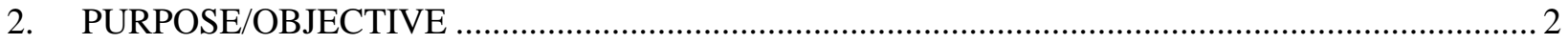

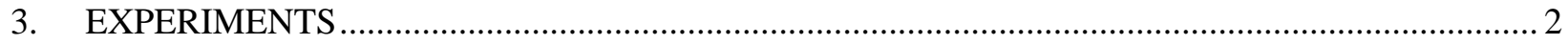

3.1 MATERIAL AND SUBMERGED ARC WELDING ….................................................... 2

3.2 CORROSION TEST COUPONS PREPARATION AND MONITORING SENSORS

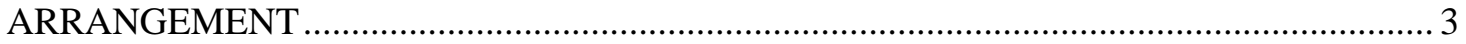

3.3 ACCELERATED CORROSION TESTING AND MONITORING ...................................... 4

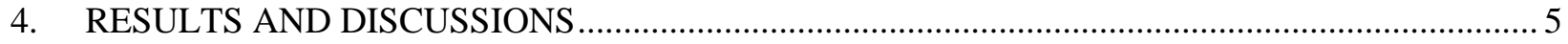

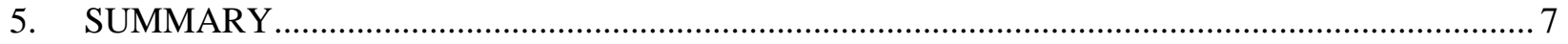




\begin{abstract}
In this report, the salt mist corrosion testing at controlled temperature was carried out successfully on 304L SS submerged arc welded coupons using a Unifog Dispersion Tower at ORNL. An in-situ corrosion monitoring system from Intelligent Automation, Inc. (IAI) was used for data collection in the salt spray chamber and ran smoothly during the corrosion test. Samples, device selection, sensor attachments, and experimental procedures are discussed. No visible corrosion or crack propagation on the weld coupon was seen after about a month of corrosion exposure.
\end{abstract}

\title{
1. BACKGROUND
}

Storage of spent nuclear fuel (SNF) is occurring for longer periods than initially intended. It is important to assess the lifetime extension of dry storage systems (DSS) with the ability to accurately monitor and predict material degradation so that corrective maintenance actions can be taken. The possibility of chloride-induced stress corrosion cracking (CISCC) in welded stainless-steel DSSs for SNF has been identified as a potential concern regarding long-term performance of the canister's containment boundary. Improved understanding of the risk of SCC to interim storage canisters has been identified as a critical data gap in analyses by the DOE Nuclear Waste Technical Review Board (NWTRB), and the Electric Power Research Institute (EPRI). Thus, there is a critical need for advanced monitoring system and analysis tools to appropriately capture and process massive amounts of measurement data and extract timely, actionable information in order to provide better canister health awareness.

To address this critical need, Intelligent Automation, Inc. (IAI) proposed to develop an innovative in-situ DSS structural health monitoring system for real-time canister health and integrity monitoring. The proposed system combines an IAI developed sensor system together with a robotic platform to deliver the sensor nodes to the susceptible spots. At the heart of the proposed system is a specially designed sensor system which continuously monitors a crack-related acoustic emission event in a large area with minimal sensor installation. The recorded crack event and location will be evaluated to determine the severity.

ORNL's Materials Science and Technology Division and the Reactor and Nuclear Systems Division have a long research and development $(R \& D)$ history and expertise in advancing the fundamental science of nuclear reactor structure and materials, and in developing applied innovative repairing technologies and solutions. In addition, ORNL has extensive experience and unique equipment in remediation of a DSS, developing novel welding and repair welding technologies, local stress control and relief, and crack mitigation methods. ORNL's unique expertise in DSS design, production, characterization, welding, and corrosion testing is not otherwise available in the domestic sector, and ORNL is not in direct competition with any other US commercial or research entity.

In this report, the salt mist corrosion testing at controlled temperature was carried out successfully on 304L SS submerged arc welded coupons by Unifog Dispersion Tower at ORNL. An in-situ corrosion monitoring system from IAI was used for data collection and in operation during the corrosion test. All recorded data have been sent to IAI for further analysis. No visible corrosion or crack propagation on the weld coupon was seen after about a month of corrosion testing. The device, attachment, and the testing may need modification in the future study. 


\section{PURPOSE/OBJECTIVE}

The purpose of this project is to develop an in-situ continuous monitoring system for real-time canister structural health and integrity monitoring. ORNL will provide representative test CISCC repaired specimens and validate the IAI developed monitoring system in a corrosion environment.

\section{EXPERIMENTS}

\subsection{MATERIAL AND SUBMERGED ARC WELDING}

The material used in this project is 0.5 " thick 304L stainless steel (304L SS) certified to ASME standard SA240. The chemical composition (weight percentage) is shown in Table 1 [North American Stainless, 2018]. Submerged arc welding (SAW) was applied to the 304L SS plates to produce welds representing joints in SNF canisters. The SAW procedure was developed and qualified following the American Society of Mechanical Engineers (ASME) Boiler and Pressure Vessel Code prior to this study [ASME, 2013; Tang, July 2019]. A double-V welding groove was machined along joining edges and double-side SAW was used to join the two plates together with one SAW pass on each side. Lincolnweld $\Phi 2.4 \mathrm{~mm}$ (3/32 in.) diameter 308L welding wire and Lincolnweld P2007 flux were used as the welding consumables. The power source was a Miller IntelliweldTM 650, and the weld controller was a Miller Automatic 1DA. The SAW was carried out with a constant voltage control mode. Welding parameters are listed in Table 2.

Table 1. Chemical composition of the 304/304L SS (North American Stainless, 2018), wt\%

\begin{tabular}{|c|c|c|c|c|c|c|c|}
\hline $\mathrm{C}, \%$ & $\mathrm{Cr}, \%$ & $\mathrm{Mn}, \%$ & $\mathrm{Ni}, \%$ & $\mathrm{P}, \%$ & $\mathrm{~S}, \%$ & $\mathrm{~N}, \%$ & $\mathrm{Si}, \%$ \\
\hline 0.0271 & 18.0525 & 1.7950 & 8.0270 & 0.0320 & 0.0010 & 0.0592 & 0.2395 \\
\hline
\end{tabular}

Table 2. Submerged arc welding parameters

\begin{tabular}{|c|c|c|c|}
\hline Welding current, $\mathrm{A}$ & Welding voltage, $\mathrm{V}$ & Welding speed, $\mathrm{mm} / \mathrm{sec}$ & $\begin{array}{c}\text { Welding wire feed } \\
\text { speed, } \mathrm{mm} / \mathrm{sec}\end{array}$ \\
\hline 450 & 30 & 8.47 & 59.3 \\
\hline
\end{tabular}

After SAW, the weld was cut into 4.5" X 12" size coupons for the accelerated corrosion test, as shown in Figure 1.

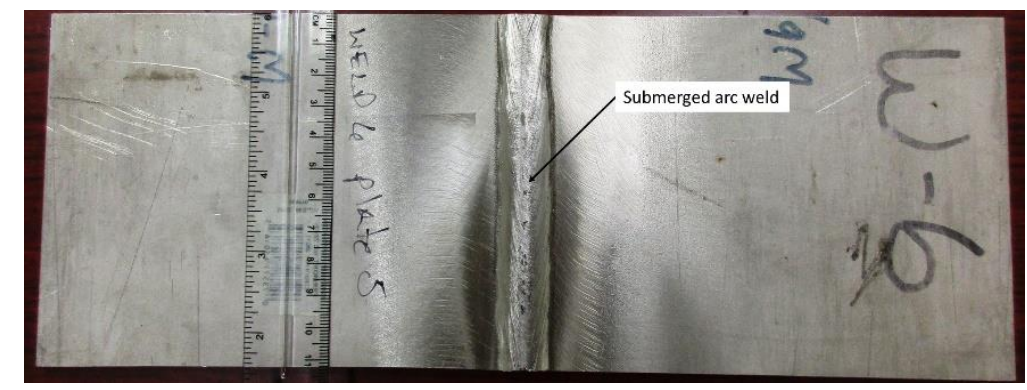

Figure 1. Submerged arc weld coupon for corrosion test 


\subsection{CORROSION TEST COUPON PREPARATION AND MONITORING SENSOR ARRANGEMENT}

Two weld coupons were prepared for the corrosion test, one coupon was prepared for as welded condition, the second coupon was modified to include an artificial crack in the weld. The opened crack simulated the CISCC in actual SNF canisters. As we have discovered in our previous study, the principal welding tensile residual stress direction in the heat affected zone (HAZ) is along the welding direction [Tang, November 2019], therefore, the potential CISCC would most likely be perpendicular to the principal tensile residual stress or the welding direction. The artificial crack was opened in the weld using a wire electrical discharge machine (wire EDM). It was perpendicular to the welding direction and crack tips were located at the weld toes. In the welded joint, the HAZ is the most sensitive metallurgical zone for CISCC. Our previous study showed that in the HAZ, welding tensile residual stress values increase as the measuring spot moves closer to the weld metal zone (WMZ) [Tang, November 2019]. Therefore, the weld toe, which is the interface of the WMZ and HAZ, is the least corrosion resistant location in this weld. A 0.001 " diameter EDM wire was used to open the crack, resulting in a width of 0.0125 ". The artificial crack opened coupon is shown in Figure 2.

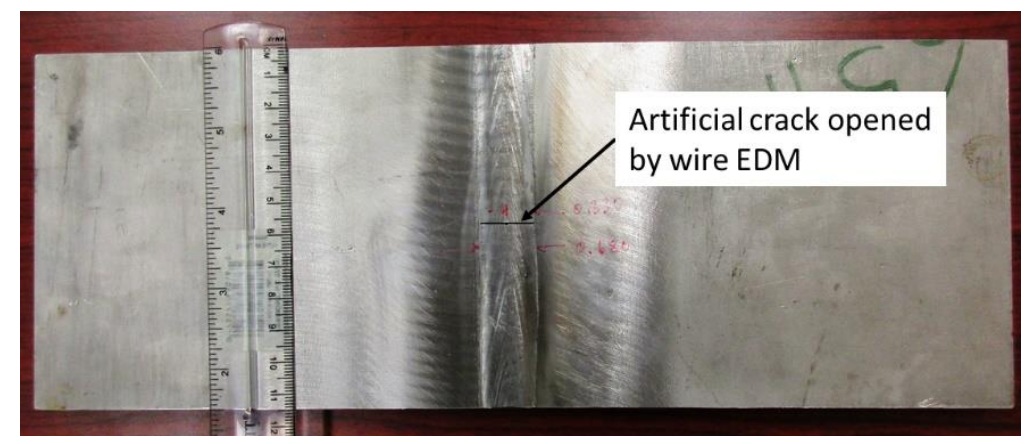

Figure 2. Submerged arc weld coupon with artificial crack

All monitoring devices, including crack propagation signal collecting sensors, signal collecting devices, and control software, were received from IAI. Two sensors were attached to each weld coupon on both sides of the weld using hot melt glue. One was 2" away from the weld toe/crack tip, and the other one was 3 " away from the weld toe/crack tip. Sensor IDs corresponding to corrosion test coupons and locations are listed in Table 3. Corrosion test weld coupons with monitoring sensors attached are shown in Figure 3.

Table 3 Signal collecting sensors ID and locations

\begin{tabular}{|c|c|c|}
\hline Sensor ID & Coupon & Distance to weld toe, in \\
\hline$\# 1$ & As welded + artificial crack & 2 \\
\hline$\# 2$ & As welded + artificial crack & 3 \\
\hline$\# 3$ & As welded & 2 \\
\hline$\# 4$ & As welded & 3 \\
\hline
\end{tabular}

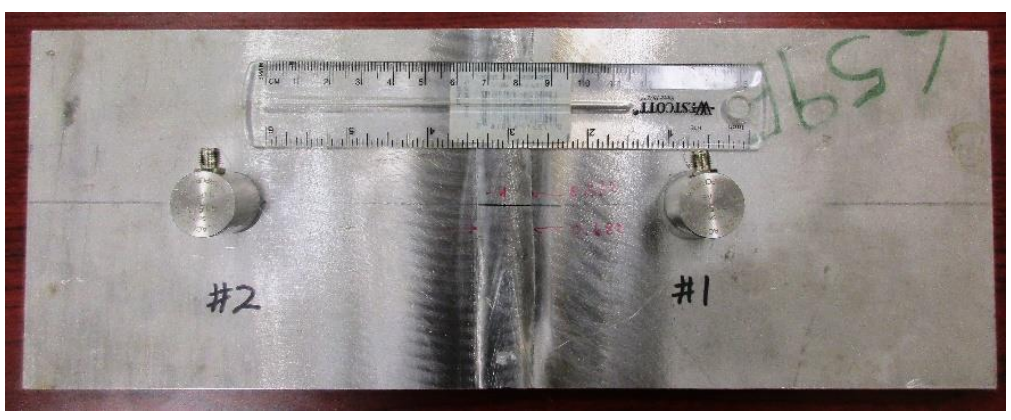




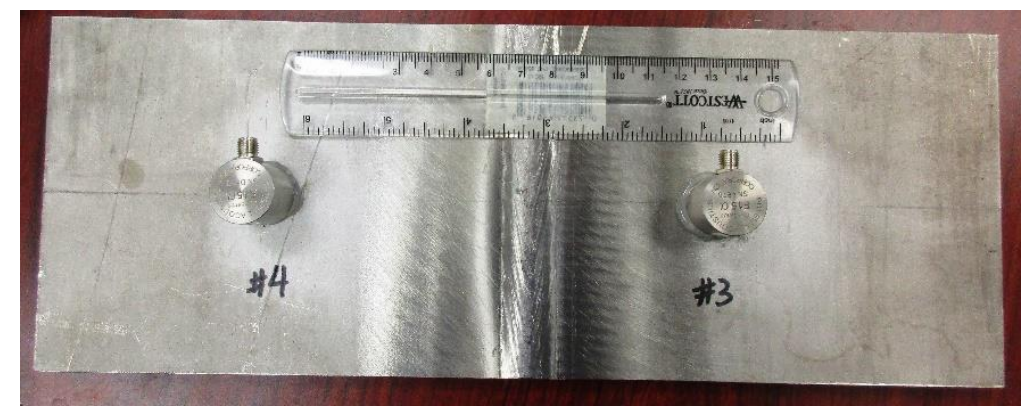

Figure 3. Submerged arc weld coupon with sensors attached for corrosion test.

Top, weld coupon with artificial crack; bottom, weld coupon without artificial crack.

\subsection{ACCELERATED CORROSION TESTING AND MONITORING}

The corrosion test was carried out in a salt fog cabinet called Unifog Dispersion Tower manufactured by Auto Technology. The Unifog Dispersion Tower contains adjustable cone for uniform collection rates, salt spray atomizer nozzle, internal reservoir with cover, pick-up tube and filter assembly. It supplies condensing humidity and liquid mist during the corrosion test. The Unifog Dispersion Tower used for the corrosion test is shown in Figure 4. The picture of test coupons inside the test chamber is shown in Figure 5 and the whole monitoring system setup is shown in Figure 6. The accelerated corrosion test used 5\% $\mathrm{NaCl}$ solution as the media, and the testing temperature was maintained to $35^{\circ} \mathrm{C}$.

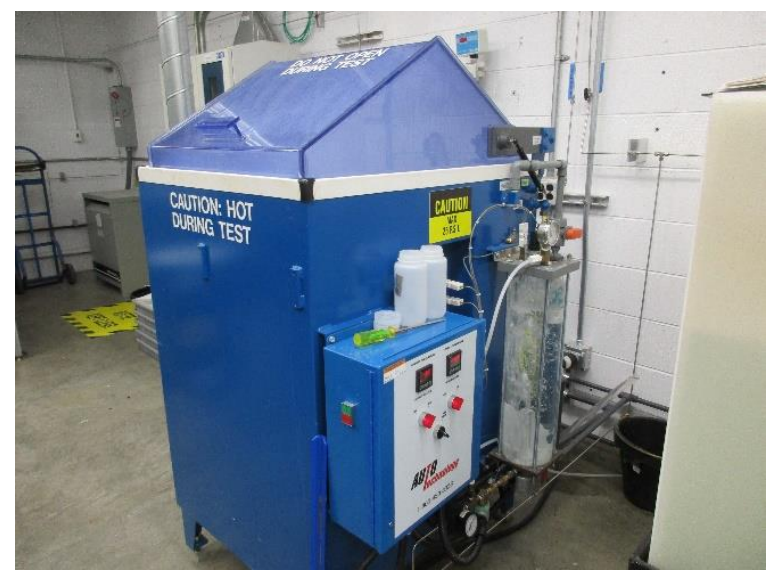

Figure 4. Unifog Dispersion Tower 


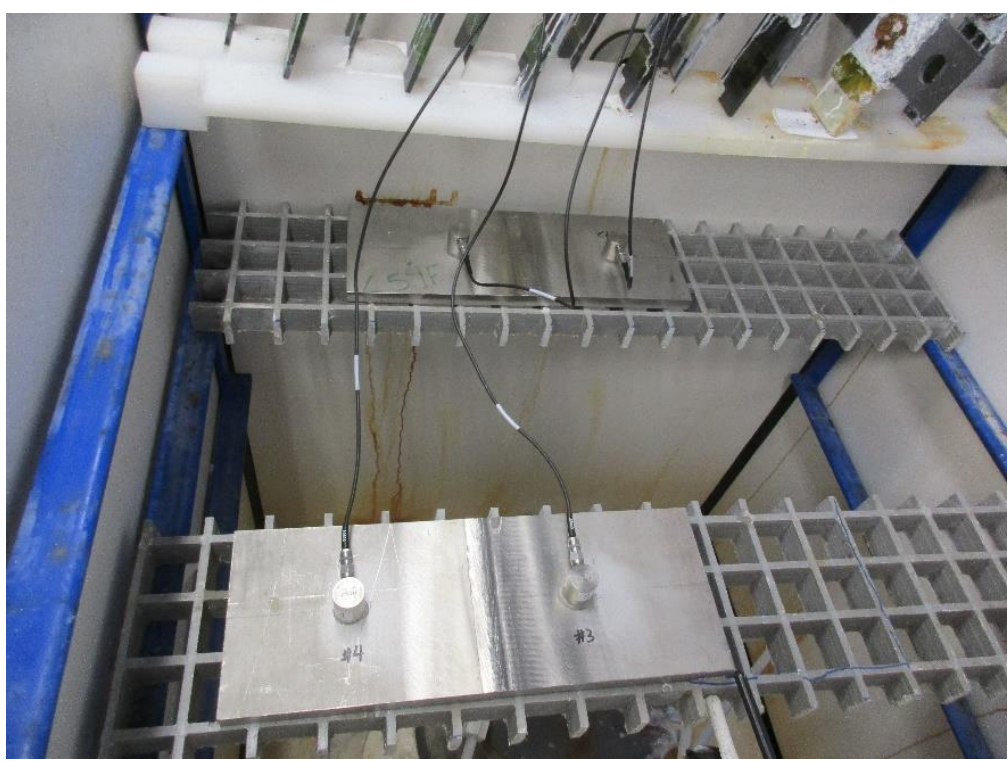

Figure 5. Submerge arc weld coupon in the corrosion testing chamber

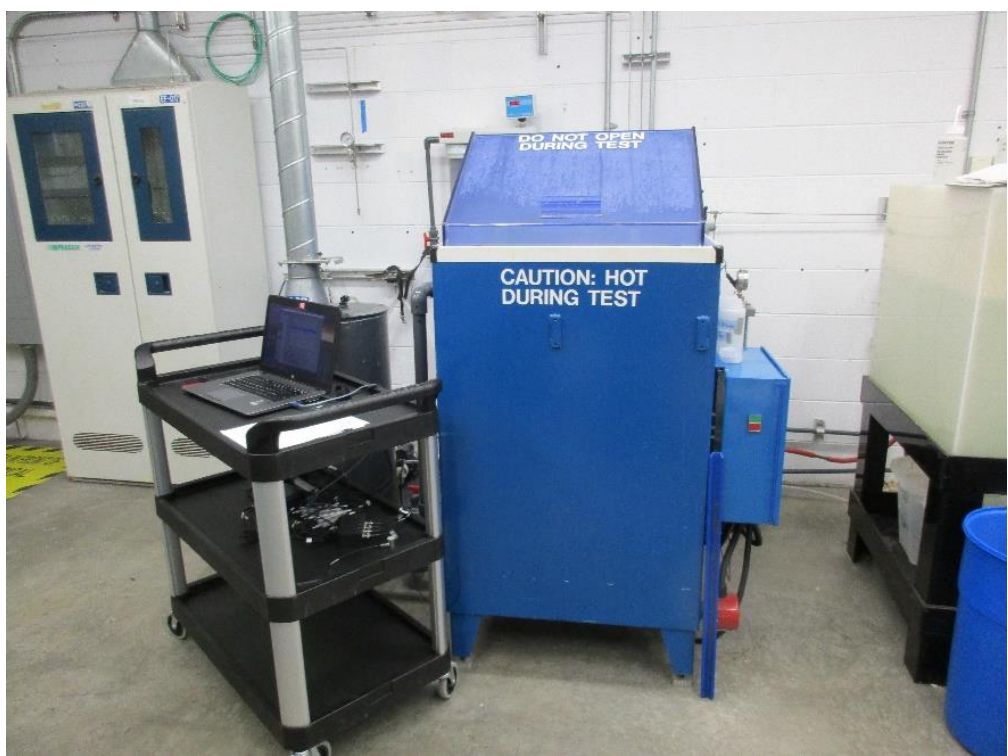

Figure 6. Corrosion testing and monitoring system setup

After the monitoring system has been setup, the accelerated corrosion test was running continuously except weekends and holidays with continuous data collection throughout the test period. The corrosion test and data captured were checked at least once a day. The Unifog Dispersion Tower was maintained daily and the test chamber was cleaned after the machine was shut down for weekends and holidays. The data captured was copied and sent to IAI every week while the test was running.

\section{RESULTS AND DISCUSSIONS}

All recorded data during corrosion testing has been sent to IAI, for analysis at IAI.

Hot melt glue was used to attach monitoring sensors onto the corrosion testing coupons. Attached sensors were evaluated using artificial sound resulting in valid responses. However, in several occasions, 
detached sensors were noticed after about a week of corrosion testing in the test chamber. The sensor detaching was probably caused by a number of factors including, attachment technique, the low power glue gun $(25 \mathrm{~W})$, the corrosive environment, and others. Figure 7 shows that the $\# 2$ sensor detached from the testing coupon after testing in the corrosion environment for about a week. This detaching of sensors also affected the recorded signal amplitude. In the future, a more reliable sensor attaching method/technique should be applied to ensure the recorded signal quality.

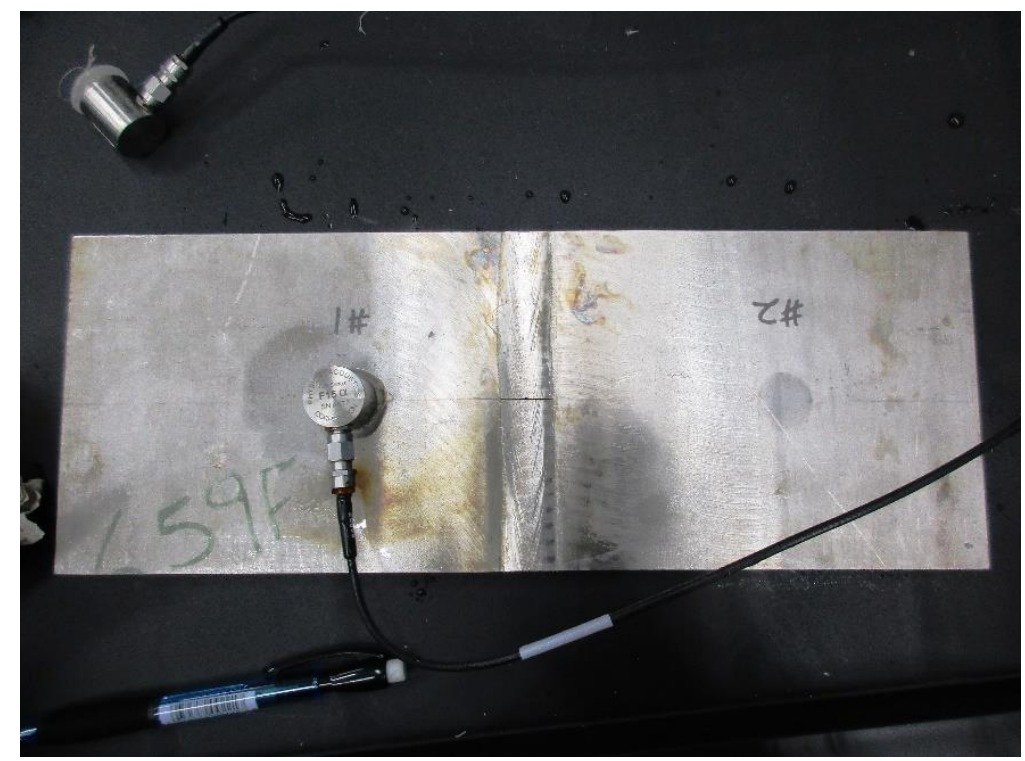

Figure 7. The \#2 sensor detached from the coupon after a week of corrosion testing.

The sensors were observed to be very sensitive. Operations such as the turning on and off of the Unifog Dispersion Tower or movement of the coupon would trigger a signal response. Those false signal recordings can be largely suppressed with the use of a proper threshold setpoint in the software. Nevertheless, taking detailed notes of the experimental, maintenance procedures, and time of occurrence are very useful to identify false recorded signals that may otherwise influence the analysis.
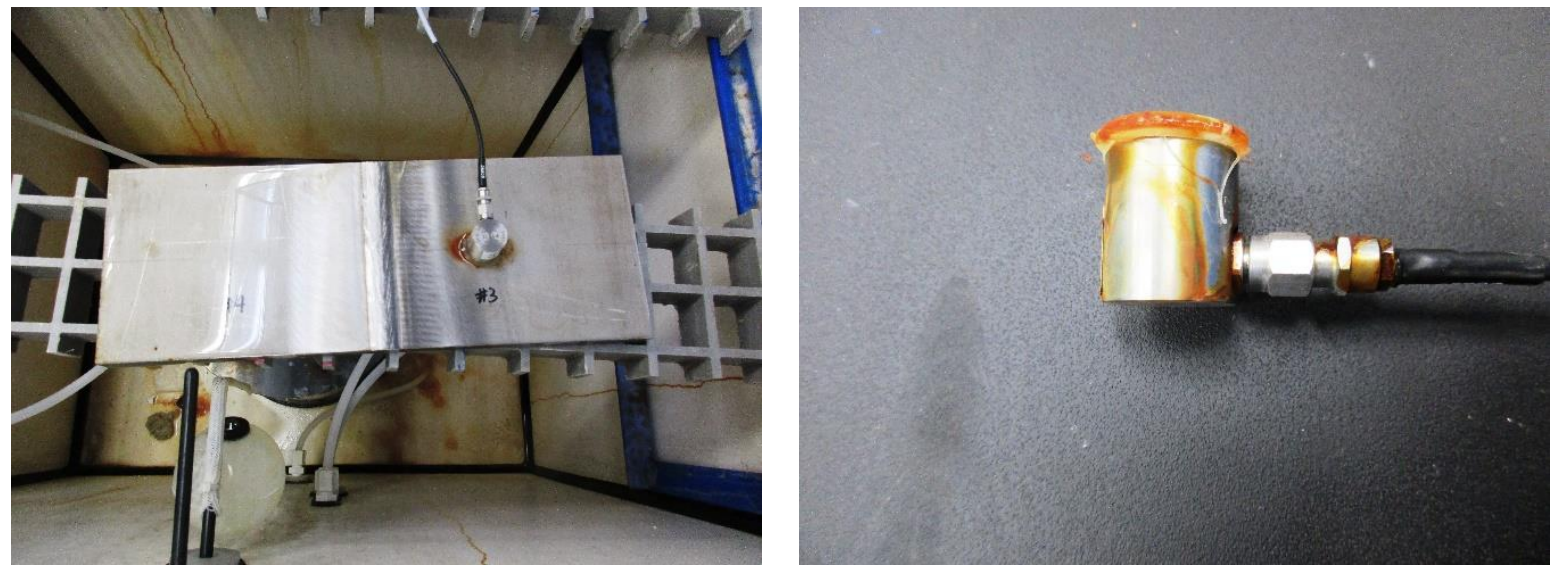

Figure 8. Traces of rusting on the weld coupon (Left) and the monitoring sensor (Right) after a few weeks of corrosion testing.

Traces of rusting were observed on the weld coupon surface and monitoring sensors after a few weeks of corrosion testing in the Unifog Dispersion Tower, shown in Figure 8. Thorough observation identified that the rust was not initiated at the coupon or the sensor surfaces, but at connectors between the sensor 
and the cable, see Figure 9 for details. Further observation/examination is needed to identify the rusting initiation spot after the corrosion testing.

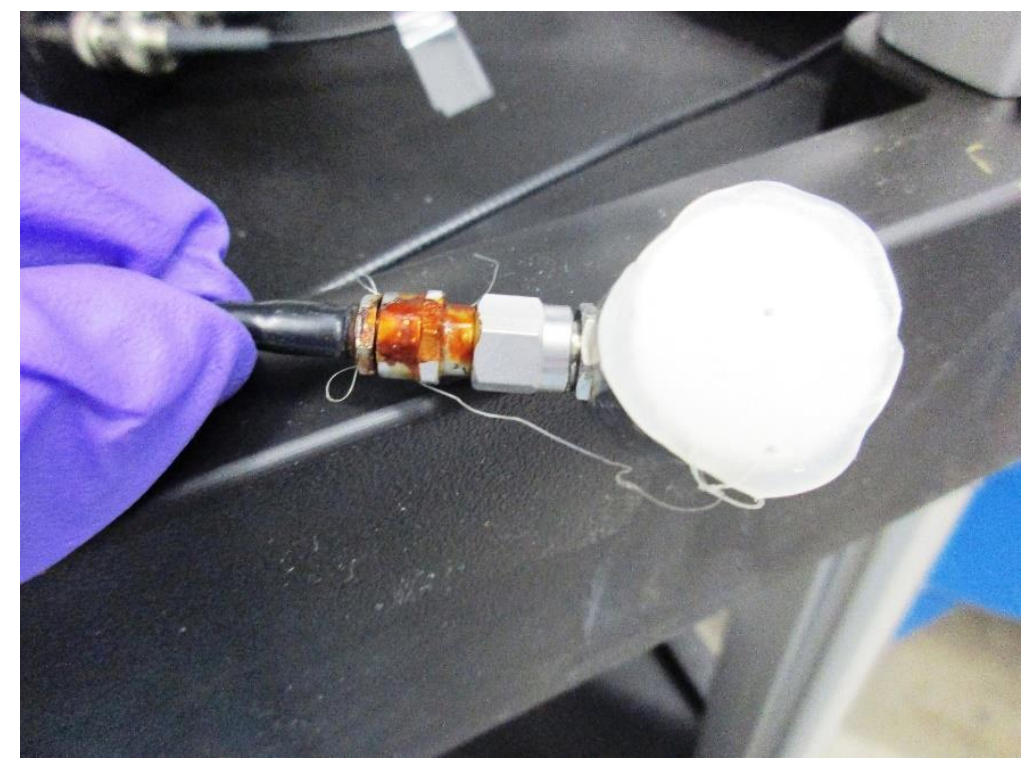

Figure 9. Rusting at the connector of the sensor and the cable.

After about a month of corrosion testing, visual inspection showed no obvious corrosion on the weld coupon surface and no noticeable crack propagation at crack tips pre-opened by wire EDM. There could be micro-level changes at the crack tips. A longer duration test is required to allow for visual observation of corrosion.

\section{SUMMARY}

The salt mist corrosion testing at controlled temperature was carried out successfully on 304L SS submerged arc welded coupons using a Unifog Dispersion Tower at ORNL. An in-situ corrosion monitoring system from IAI was used for data collection and in operation during the corrosion test. All recorded data have been sent to IAI for further analysis. No visible corrosion or crack propagation on the weld coupon was seen after about a month of corrosion testing. The device, attachment, and the testing may need modification for future study.

\section{ACKNOWLEDGEMENT}

The authors gratefully acknowledge the welding operation, coupons preparation and discussions of Roger Miller, Doug Kyle and Alan Frederick at ORNL, the corrosion testing operation and maintenance of Jiheon Jun and George W. Garner at ORNL, the report reviewing of Jiheon Jun and Kevin Faraone at ORNL, and the technical discussion and in-situ monitoring system setup instruction of Bin Lin and Xiaoliang Zhao at IAI.

\section{REFERENCE}

American Society of Mechanical Engineers (ASME), 2013. ASME Boiler \& Pressure Vessel Code IX, Qualification Standard for Welding, Brazing, and Fusing Procedures; Welders; Brazers; and Welding, Brazing, and Fusing Operators. 
North American Stainless, 2018. Inspection Certificate \#377084 01.

Wei Tang, Stylianos Chatzidakis, Roger Miller, Jian Chen, Doug Kyle, John Scaglione, Caleb Schrad, Welding Process Development for Spent Nuclear Fuel Canister Repair. Proceedings of the ASME 2019 Pressure Vessels \& Piping Conference, PVP2019, July 14-19, 2019, San Antonio, Texas, USA.

Wei Tang, Stylianos Chatzidakis, Roger Miller, Caleb Schrad, Joshua Rittenhouse, John Scaglione, Stainless Steel Plates Repair Welding and Post-Weld Characterization. 2019 AWS Professional Program, Fabtech, November $11-14,2019$, Chicago, IL, USA. 